\title{
STRATEGI PENGEMBANGAN WISATA HALAL KOTA BOGOR DENGAN MENGOPTIMALKAN INDUSTRI KREATIF
}

\section{DEVELOPMENT STRATEGIES HALAL TOURISM IN BOGOR BY OPTIMIZING THE CREATIVE INDUSTRY}

\author{
D. Hariani' ${ }^{1}$ S. Dinitri²
}

Sekolah Tinggi Pariwisata Bogor, Jalan Curug Mekar No.17 Yasmin Bogor 16113, Jawa Barat, Indonesia. E-mail: bhi.dinahariani@gmail.com ${ }^{1}$, seruni.dinithree@gmail.com

\begin{abstract}
ABSTRAK
Penelitian ini bertujuan untuk mengetahui potensi wisata halal yang ada di kota Bogor, dan mencari strategi pengembangan industri kreatif yang bisa digunakan dalam pengembangan wisata halal di kota Bogor terutama di kawasan Bangbarung. Penelitian ini menggunakan analisis deskriptif kuantitatif, kualitatif, dan tehnik analisis yang digunakan adalah analisis SWOT. Hasil penelitian menunjukan kawasan Bangbarung siap menjadi kawasan wisata halal di Bogor. Kawasan Bangbarung didukung dengan beberapa industri kreatif seperti kuliner, fesyen dan spa yang sudah mengikuti persyaratan pariwisata Halal seperti ketersediaan Logo atau sertifikasi Halal, ketersediaan ruang sholat dan wudhu, toilet yang bersih, pakaian pelayan yang sesuai Strategi untuk pengembangan produk di daerah Bangbarung masuk ke dalam kesadaran untuk menjaga dan mempertahankan. Meskipun daerah Bangbarung siap menjadi tujuan wisata halal di Bogor tetapi masih membutuhkan dukungan dari pemerintah daerah untuk sertifikasi halal karena masih ada restoran dan tempat makan di daerah itu yang tidak memiliki sertifikasi halal atau logo dan membuat paket wisata halal untuk menambah jumlah wisatawan muslim ke daerah Bangbarung. Peran masyarakat juga penting untuk menjaga dan mempertahankan pengembangan pariwisata halal di daerah Bangbarung.
\end{abstract}

Kata Kunci: Wisata Halal, Bogor, Industri Kreatif

\begin{abstract}
The aim of this research was to identify the potential for halal tourism in the city of Bogor, and to search a strategy for creative industrial development halal tourism in Bogor city especially in Bangbarung region. The study uses qualitative approach and analysis using SWOT analysis. Research has shown that Bangbarung areas are supported by several by several creative industry such as culinary, fashion and spas already following halal tourism requirements such as the avaibility of logos or halal certification, the availability of prayer rooms and the wudhu room, clean toilets, service clothing that fit the development of products in Bangbarung area enters the consciousness to guard and maintain. Although Bangbarung areas are ready to become halal tourist purpose in Bogor but still need the support of local goverments for halal certification because there are still restourants and places in the area that do not have halal certification and make halal tourist package to increase muslim tourist to Bangbarung. The role of community is also important to preserve and maintain Halal tourism development in the Bangbarung area.
\end{abstract}

Keyword: Halal Tourism, Bogor, Creative Industry 


\section{Dina Hariani. 2020. Strategi Pengembangan Wisata Halal Kota Bogor Dengan Mengoptimalkan Industri Kreatif. Jurnal Syarikah 6(2): $209-220$.}

\section{PENDAHULUAN}

Tren wisata Halal dunia meningkat seiiring dengan perkembangan industri pariwisata diseluruh dunia. Wisata Halal juga meningkat menjadi salah jenis wisata baru yang patut dikembangkan. Crecent Rating yang merupakan konsultan wisata halal menjelaskan bahwa jika dilihat dari populasi muslim di dunia sebanyak 1,8 milyar atau sekitar $28 \%$ dari total populasi dunia sebesar 6,4 miliar yang tersebar di 148 negara potensi terhadap pasar untuk pengembangan wisata halal (muslim) sangat besar dari total muslim di dunia, 62\% muslim berasal dari Asia Pasifik atau sama dengan sekitar 972 juta jiwa. Maka dari itu, muncullah wisata halal sebagai tren dari pariwisata saat ini.

Melihat tren tersebut, Indonesia sebagai negara dengan jumlah muslim terbanyak juga sedang fokus mengembangkan pariwisata halal. Berbagai cara dilakukan agar Indonesia dapat bersaing dengan negara Asia Tenggara lain dalam menarik wisatawan lokal maupun internasional. Di tahun 2019 ini Pemerintah Indonesia dapat berbangga hati karena mampu membuktikan potensinya sebagai destinasi wisata halal terbaik di dunia bersanding dengan Malaysia menempati peringkat pertama destinasi Wisata Halal berdasarkan standar Global Muslim Travel Index (GMTI) 2019 mengungguli 130 destinasi dari seluruh dunia. Menteri Pariwisata Arief Yahya mengharapkan dengan Indonesia menjadi destinasi wisata halal terbaik dunia maka akan semakin banyak mengundang minat wisatawan muslim dunia berkunjung ke Indonesia.

Berdasarkan Global Muslim Travel Index (GMTI) hal-hal yang dianalisis dalam kriteria wisata halal adalah berdasarkan 4 (empat) kriteria penilaian strategis, yaitu akses, komunikasi, lingkungan, dan layanan. Sebuah destinasi wisata dapat dikatakan sebagai wisata halal jika memenuhi kebutuhan utama wisatawan muslim. Dikutip dari GMTI (2019), ada 6 kebutuhan utama wisatawan muslim pada saat sedang berwisata, yaitu: tersedianya makanan halal (tidak ada alkohol, daging babi, dan sejenisnya), tersedianya fasilitas ibadah atau tempat sholat, kamar mandi dengan air untuk wudhu, pelayanan saat bulan Ramadhan, misalnya santapan berbuka dan sahur, pencantuman label non-halal apabila terdapat makanan yang tidak halal, dan fasilitas rekreasi yang menjaga privasi, tidak bercampur secara bebas.

Kota Bogor sendiri terletak di provinsi Jawa Barat dan terletak tidak jauh dari Ibukota negara. Letak Kota Bogor berjarak kurang lebih 60 kilometer dari Jakarta. Kota Bogor meiliki iklim udara yang sejuk karena mempunyai daya tarik wisata alam yang alami yaitu Kebun Raya Bogor serta terkenal dengan wisata kulinernya sehingga membuat banyak wisatawan rela mendatangi kota ini dengan motivasi yang berbeda-beda.

\section{MATERI DAN METODE}

Wisata halal merupakan konsep yang relatif baru dalam industri pariwisata. Pariwisata halal telah diperkenalkan sejak tahun 2000 dari pembahasan pertemuan OKI. Pariwisata halal merupakan suatu permintaan wisata yang didasarkan pada gaya hidup dan kebutuhan wisatawan muslim selama liburan. Selain itu, pariwisata halal merupakan pariwisata yang fleksibel, rasional, sederhana dan seimbang. Pariwisata ini bertujuan agar wisatawan termotivasi untuk mendapatkan kebahagiaan dan berkat dari Allah SWT (Munirah, 2012).

Definisi pariwisata halal menurut Kementrian Pariwisata Indonesia tahun 2012 adalah seluruh kegiatan yang didukung oleh berbagai fasilitas serta layanan yang disediakan masyarakat, 
pengusaha, pemerintah, dan pemerintah daerah yang memenuhi ketentuan syariah. Di dalam Muri (2014) disebutkan "Halal is an Arabic word which means lawful in Sharia, and refers to what a muslim can eat satisfactorily. In general it is required to carry out the contraindications of pork, alcohol, and its derivative, and to be processed according to Sharia also about the other foods, and it is also forbidden that Halal food and the other food contact."

Kebalikan dari halal disebut haram atau Non-Halal. Status halal ditujukan kepada makanan, kosmetik, dan lain-lain yang diproduksi tanpa menggunakan produk babi, alkohol, dan lain-lain yang memang dilarang dalam agama Islam. Bahkan makanan seperti ayam dan daging pun mesti diproses mulai dari penyembelihannya sampai dengan proses masak dengan menggunakan cara Islam. Selain itu, proses keseluruhan dari seluruh proses bahan makanan, seperti jalur produksi, penyimpanan, transportasi, penyajian, dan penjualannya harus dengan cara yang halal atau sesuai dengan syariat Islam. Saat ini telah terjadi evolusi dalam industri halal hingga penyebarannya meluas ke berbagai produk, seperti produk keuangan (perbankan dan asuransi) produk gaya hidup (travel, hospitalitas, rekreasi, mall dan perawatan kesehatan). Sektor ekonomi Islam yang telah mengalami pertumbuhan yang signifikan dalam produk gaya hidup di sektor pariwisata adalah wisata halal.

Menurut Howkins (2001), ekonomi kreatif adalah kegiatan ekonomi dimana input dan output-nya adalah gagasan. Ekonomi kreatif adalah pemanfaatan cadangan sumber daya yang bukan hanya paling baru, tapi juga tidak terbatas, seperti ide, gagasan, bakat atau talenta dan kreativitas. Di era kreatif ini nilai ekonomi dari suatu produk atau jasa tidak lagi ditentukan oleh bahan baku atau sistem produksi seperti pada era industri, akan tetapi lebih kepada pemanfaatan kreativitas dan penciptaan inovasi melalui 5 (lima) perkembangan teknologi yang semakin maju. Industri tidak bisa bersaing di pasar global hanya dengan mengandalkan harga atau kualitas produk, tetapi harus bersaing berdasarkan inovasi, kreativitas dan imajinasi.

Terdapat beberapa sub-sektor yang merupakan industri berbasis kreativitas di Indonesia berdasarkan pemetaan industri kreatif yang telah dilakukan oleh Departemen Perdagangan Republik Indonesia. Beberapa sub sektor tersebut adalah: periklanan, arsitektur, pasar barang seni, kerajinan, desain, fesyen, video, film dan fotografi, permainan interaktif, musik, seni pertunjukkan, penerbitan dan percetakan, layanan komputer dan peranti lunak, televisi dan radio, riset dan pengembangan, dan kuliner.

Penelitian ini menggunakan metode deskriptif dengan pendekatan kuantitatif dan kualitatif. Hal ini dilakukan atas dasar pertimbangan bahwa metode penelitian deskriptif bertujuan untuk menggambarkan hasil penelitian secara sistematis, faktual dan akurat fakta, karakteristik dan hubungan antar fenomena yang diselidiki (Sugiyono, 2010).

Peneliti menggunakan pendekatan kuantitatif untuk membuat peringkat data kualitatif sehingga lebih mudah untuk menarik kesimpulan. Menurut Sugiyono (2010) dijelaskan bahwa penelitian kuantitatif adalah penelitian dengan memperoleh data berupa angka atau data kualitatif yang diharapkan sedangkan pendekatan kualitatif bertujuan agar peneliti mendapatkan informasi dalam melihat potensi pariwisata halal di Bogor khususnya di kawasan Bangbarung.

Penelitian Strategi Pengembangan Wisata halal Kota Bogor dengan mengoptimalkan industri kreatif ini akan menggunakan kawasan Bangbarung yang ada di kota Bogor. Industri kreatif yang diteliti dalam penelitian ini adalah kuliner, spa, dan fesyen. 


\section{HASIL DAN PEMBAHASAN}

Berdasarkan penelitian yang telah dilakukan peneliti dengan melaksanakan observasi dan wawancara kepada pelaku usaha di Kota Bogor, Dinas Pariwisata Kota Bogor, MUI Kota Bogor, akademisi serta wisatawan di Kota Bogor, kawasan Bangbarung terpilih sebagai objek penelitian di wilayah kota Bogor. Kawasan Bangbarung memiliki beberapa usaha yang menggunakan konsep industri kreatif dibandingkan kawasan lain yang ada di kota Bogor. Bangbarung terletak di kecamatan Tegal Gundil, Bogor Utara, Kota Bogor. Kawasan Bangbarung sampai dengan saat ini merupakan kawasan wisata kuliner karena hampir sebagian besar kawasan tersebut dipenuhi oleh tempat-tempat makan yang unik dan bervariatif. Berbagai penjual makanan dikawasan tersebut mayoritas menempati bangunan berbentuk rumah, kios atau ruko. Berbagai jenis sajian makanan terdapat di kawasan ini. Sebut saja berbagai macam aneka bakso, ayam, makanan internasional, seafood dengan desain fasilitas yang instagramable, sampai minuman kekinian juga berada di kawasan tersebut. Ketika Ramadhan tiba, kawasan ini juga dipenuhi oleh tenda-tenda kecil untuk menyajikan berbagai makanan untuk berbuka puasa.

Selain sebagai objek wisata kuliner, kawasan Bangbarung sendiri memiliki toko fesyen untuk wanita Muslim seperti Myra Moslem Fashion Boutique, salon khusus untuk wanita House of Aisya, berbagai klinik kecantikan dan juga memiliki masjid yang cukup besar yang terletak di tengah dari daerah tersebut.

Kondisi lingkungan internal dan eksternal memiliki faktor-faktor yang terdiri dari kekuatan, kelemahan, peluang dan ancaman yang bisa menjadi pengaruh terhadap pengembangan rantai nilai (value chain) kualitas produk utama (Kawasan wisata Halal) sehingga analisis data internal dan eksternal dalam mengembangkan produk yang merupakan rantai pendukung (supply chain) dikembangkan berdasarkan fenomena pengembangan wisata halal yang relevan.

Analisis lingkungan internal pertama adalah memasukkan bobot pada tabel dan rating pada tabel dari masing-masing variabel dan indikator ke dalam matriks Internal Factor Analysis Summary (IFAS) berdasarkan hasil kuesioner, wawancara, observasi langsung dan juga berdasarkan penelitian sebelumnya, seperti yang terlihat pada tabel berikut ini:

Jika rata-rata rating 2.5 ke bawah menandakan secara internal kawasan adalah lemah. Jika diatas 2.5 menandakan secara internal kawasan mempunyai posisi yang kuat. Para stakeholders menganggap bahwa berbagai indikator atraksi maupun amenity memiliki kekuatan untuk menjadikan kawasan Bangbarung sebagai kawasan wisata halal. Namun untuk indikator paket wisata halal sendiri masih menjadi kelemahan. Hal ini selaras dengan memang belum adanya paket wisata halal yang ditawarkan pihak tour dan travel yang berada di kawasan Bangbarung.

Analisis selanjutnya adalah memasukan bobot pada tabel dan rating dari masingmasing variabel dan indikator ke dalam matriks Internal Factor Analysis Summary (IFAS) seperti pada tabel berikut ini

Dalam analisis eksternal ini upaya yang dilakukan adalah mengetahui seberapa kuat peluang dan ancaman yang berasal dari luar manajemen penyedia jasa pariwisata dalam proses mengembangkan produk pariwisata. Pembobotan dan peratingan dinilai oleh berbagai pemangku kepentingan pariwisata. Analisis selanjutnya adalah memasukan bobot masing-masing indikator dari tiap-tiap variabel pada lingkungan eksternal sesuai dengan pembobotan pada tabel dan penilaian informan pada tabel. Skor analisis lingkungan eksternal dapat dilihat pada tabel berikut ini

Strategi umun yang dapat direncanakan adalah menggunakan kesempatan yang ada sebaik-baiknya, mencoba mengantisipasi dan menanggulangi ancaman yang ada, menggunakan kekuatan sebagai dasar operasional pengelolaan dan memanfaatkannya semaksimal mungkin, serta berupaya untuk mengurangi dan menghilangkan kelemahan yang masih ada.

Berdasarkan pengolahan data, hasil analisis faktor internal dan eksternal telah diperoleh masing-masing total skor faktor internal dan eksternal yaitu 2.81 dan 2.50. Langkah selanjutnya membuat ploting pada matriks internal dan eksternal Matrik IE berupa 
diagram sembilan sel. Berdasarkan Matrik Internal Eksternal (IE) menunjukan bahwa pertemuan antara nilai lingkungan internal dan lingkungan eksternal berada pada sel $\mathrm{V}$ yakni strategi pertahankan dan pelihara. Strategi yang dapat diterapkan pada sel $\mathrm{V}$ adalah penetrasi pasar dan pengembangan produk.

Strategi yang dijabarkan saat ini dapat dikatakan masih bentuk umum yang sangat mengambang dan belum jelas arahnya. Perumusan strategi sebaiknya diikuti oleh suatu rencana konkret yang disebut program yang nanti jika tersedia anggaran dapat direalisasikan menjadi program aksi atau proyek pengembangan. Berdasarkan SWOT analisis di atas ada beberapa strategi pengembangan yang dapat digunakan untuk menjadikan kawasan Bangbarung sebagai kawasan wisata halal di kota Bogor yaitu strategi untuk pengembangan produk di daerah Bangbarung masuk ke dalam kesadaran untuk menjaga dan mempertahankan. Meskipun daerah Bangbarung siap menjadi tujuan wisata halal di Bogor tetapi masih membutuhkan dukungan dari pemerintah daerah untuk sertifikasi Halal karena masih ada restoran dan tempat makan di daerah itu yang tidak memiliki sertifikasi Halal atau logo dan membuat paket wisata Halal untuk menambah jumlah wisatawan muslim ke daerah Bangbarung. Peran masyarakat juga penting untuk menjaga dan mempertahankan pengembangan pariwisata halal di daerah Bangbarung.

\section{KESIMPULAN DAN IMPLIKASI}

Berdasarkan penelitian yang dilakukan mengenai strategi pengembangan pariwisata Halal dengan mengoptimalkan industri kreatif di kota Bogor ditemukan bahwa kawasan Bangbarung siap menjadi kawasan wisata Halal di Bogor. Kawasan Bangbarung didukung dengan beberapa industri kreatif seperti kuliner, fesyen dan spa yang sudah mengikuti persyaratan pariwisata Halal seperti ketersediaan Logo atau sertifikasi Halal, ketersediaan ruang sholat dan wudhu, toilet yang bersih, pakaian pelayan yang sesuai dan lain-lain.
Skor IFAS adalah 2,81 dan nilai EFAS 2,50 yang menghasilkan strategi untuk pengembangan produk di daerah Bangbarung masuk ke dalam kesadaran untuk menjaga dan mempertahankan. Meskipun daerah Bangbarung siap menjadi tujuan wisata Halal di Bogor tetapi masih membutuhkan dukungan dari pemerintah daerah untuk sertifikasi Halal karena masih ada restoran dan tempat makan di daerah itu yang tidak memiliki sertifikasi Halal atau logo dan membuat paket wisata Halal untuk menambah jumlah wisatawan muslim ke daerah Bangbarung. Peran masyarakat juga penting untuk menjaga dan mempertahankan pengembangan pariwisata Halal di daerah Bangbarung.

\section{DAFTAR PUSTAKA}

Akyol, M. and Kilinc, 0.2014. Internet and Halal Tourism Marketing. Electronic Turkish Studies; Volume 9/8.

Butler, R. W. 1980. The concept of a tourist area cycle of evolution: Implications for management of resources. The Canadian Geographer, 24(1), 5-12.

Cooper, D.R.\& Schindler, P.S. (2000). Business Research Methods. 7 th edition. New York: MacGraw-Hill/Irwin

Crescent Rating. 2017. Global Moslem Travel Index 2017. Diunduh dari : https://www.crescentrating.com/report s/global-muslim-travel-index-2017.html

Crescent Rating. 2019. Global Moslem Travel Index 2019. Diunduh dari : https://www.crescentrating.com/report s/global-muslim-travel-index-2019.html

Dinas Pariwisata dan Kebudayaan Kota Bogor. 2018. Data Kepariwisataan Kota Bogor.

Hariani, Dina. 2017. Pengaruh Ketersedian Fasilitas Moslem Friendly Terhadap Minat Kunjungan Kembali Wisatawan Moslem Indonesia Ke Jepang. Sekolah Tinggi Pariwisata Trisakti 
Howkins, John. 2001. The Creative Economy How People Make Money from Ideas. Penguin Grup (USA) Incorporated.

Kementerian Pariwisata dan Ekonomi Kreatif. 2012. Rencana Strategis 2012 2014 Kementerian Pariwisata dan Ekonomi Kreatif. Diunduh dari : http://www.kemenpar.go.id/post/renca na-strategis-2012-2014-kementerianpariwisata-dan-ekonomi-kreatif

Marlina, Leni. 2017. Industri Kreatif dalam Menopang Pariwisata Syariah. Diunduh dari : http://www.jabarpos.id/industrikreatif-dalam-menopang-pariwisatasyariah/

Ridwan. 2012. Perencanaan dan Pengembangan Pariwisata. Jakarta: PT. Soft Media.

Sugiyono. 2010. Metode Penelitian Pendidikan Pendekatan Kuantitatif, kualitatif, dan R\&D. Bandung: Alfabeta.

Swarbrooke, John. 2012. The Development and Management of Visitor Atrraction. 2nd Ed. Butterworth-Heinemann.

Takayuki Mori. The present condition and the subject of Halal in Japan, In comparison with Malaysia. Diunduh dari :http://www.cai.ku.ac.th/PaperARD/paper34.pdf. 